and - SH linkages, but fibrin does not (-S-Slinkage does not). (12) Fibrin is readily soluble in sodium sulphide, which disrupts - S-S- linkages. (13) Blood clotting can be inhibited by an excess of thiol compounds and by substances which react with thiol groups: (a) mercury compounds, (b) arsenic compounds of the arsenoxide type, (c) cyanides. (14) The immediate oxidation of thiol compounds by 2-methyl-1 : 4-naphthoquinone can be shown polarographically.

It is not suggested that the conversion of fibrinogen to fibrin occurs when one molecule of fibrinogen is united to another by a single - S-S- linkage, but that the fibrinogen molecule contains many potential - SH groups, and that these unite in a definite pattern forming long chains and ultimately give rise to the typical fibrin gels.

Details of the experiments which gave rise to these findings will be published elsewhere.

RAYMOND N. Lyons.

Kanematsu Memorial Institute of Pathology,

$$
\text { Sydney Hospital, }
$$

Sydney.

Feb. 13.

'Craven, R., J. Chem. Soc., 1605 (1931).

2 Novelli, A., Science, 93, 358 (1941).

\section{Methionine and the Fatty Liver of Infant Peliagrins}

ON a previous occasion, we were able to demonstrate that the intensely fatty liver is an invariable concomitant of pellagra in infants. This fatty liver responds poorly to a balanced diet with, or without, supplements of vitamin concentrates, chiefly of the B complex; it recovers slowly when treated with crude liver extract but is rapidly and completely healed by ventriculin ${ }^{1,2}$.

In order to obtain further information concerning the nature of this fatty liver, we decided to test the effects of methionine under controlled conditions. The amount of methionine available to us was just sufficient for two cases. One child was three years of age and the other fifteen months. As a control, we used another fifteen months old pellagrin. The three cases were selected, not only on the basis of the elinical criteria on admission, but also on the similarity of the liver lesion as determined microscopically.

The three cases were submitted to biopsy within an hour of admission to hospital, and when it was established that the fragment of liver was intensely fatty, with almost every cell containing a single, large globule of fat, such as is described previously in our category $1^{2}$, or type $1, b$ variety ${ }^{3}$, treatment was then instituted. The cases were put on the same basal diet of mealie meal (maize) porridge and half-strength milk and, in two cases, methionine was added in amounts stated below. Biopsy of the liver was performed in all cases soon after admission, a day after the last dose of methionine or, in the case of the control, at the end of one week.

Case 1 was a three-year-old infant. A total of $8 \mathrm{gm}$. of methionine was administered orally over four days. The treatment was stopped because the clinical condition deteriorated and the cedema became intensified. The liver, at this stage, was even worse than on admission to hospital. Treatment with a full diet and ventriculin resulted in the disappearance of the œdema fluid within four days, and the liver fat became absorbed, but at a much slower rate than in cases not pre-treated with methionine.

Case 2 was aged 15 months. A total of $11 \mathrm{gm}$. of methionine was administered orally over seven days. The elinical condition did not improve and the cedema became intensified. Another biopsy of the liver was performed and the fat was almost as abundant as at the outset of the treatment. At the end of the first week, when the administration of methionine was stopped, the ventriculin treatment was instituted. This child also recovered slowly.

Case 3 was the control and also 15 months old. On admission, the liver was indistinguishable, histologically, from those of Cases 1 and 2. This baby received no treatment other than half-strength milk and mealie meal porridge. Although the clinical condition did not improve, the liver, at the end of one week, did show some deterioration. After treatment for one week with ventriculin, the child made a rapid but uneventful recovery.

In all cases the livers were examined by fiuorescence microscopy. Typical vitamin A fluorescence was not observed in the Kupffer cells. However, many of the big droplets of fat showed a dull greenishwhite fluorescence. Popper and Chinn ${ }^{4}$ maintain, from their experiments in rats, that vitamin $A$ fluorescence disappears from the liver in choline defieiency; but in human infants we have found that the fluorescence of the fat droplets in the liver cells remains, even after treatment with methionine, and the Kupffer cells remain free from vitamin A fluorescent material.

From this investigation we conclude: (a) In conjunction with a high carbohydrate diet, methionine, in the amounts used over a short period, does not remove the fat from the livers of human pellagrins in a manner comparable with that described for ventriculin. (b) Fluorescence of the fat droplets in the livers of infants does not imply that they will respond to methionine. (c) Methionine, under present conditions stated above, neither removes the oedema, fluid nor does it lead to clinical improvement. (d) A high carbohydrate diet in infants has not the lipotropic action in children which it has in many adult pellagrins ${ }^{5}$. (e) Either methionine, in the amounts used over 4-7 days, is incapable of acting as a lipotrope in infant pellagrins, or it requires some additional clietary substance to exert its lipotropic effect as Channon et al. ${ }^{6}$ suggested from experiments in rats. (f) Ventriculin, in conjunction with a full diet, is still the best treatment for pellagra in infants. The limited amount of methionine available to us (20 gm.) prevented us from carrying out more exhaustive experiments.

We are indebted to Mr. Brown, of Glaxo Laboratories, Johannesburg, for the methionine.

T. Gmlman.

J. Gillmax.

Medical School,

University of the Witwatersrand, Johannesburg.

Feb. 28.

${ }^{1}$ Gillman, J., Gillman, T., Inglis, J., Friedlander, L., and Hammar, E., Nature, 154, $210(1944)$.

'Gillman, T., and Gillman, J., J. Amer. Med. Assoc., in the press.

-Gillman, J., and Gillman, T., in the press.

4 Popper, H., and Chinn, H., Proc. Soc. Exper. Biol. and Med., 49, 202 (1942).

${ }^{5}$ Gillman, J., and Gillman, T., in the press. Channon, H. J., Mainfold, M. C., and Platt, A. P., Biochem. J., 34,
866 (1940). 